\title{
Identificación y valoración de los Servicios Ecosistémicos del Parque Regional de las Salinas y Arenales de San Pedro del Pinatar (Murcia, España) basado en encuestas a los usuarios
}

\author{
Identification and assessment of the ecosystem services of the Salinas $y$ Arenales \\ de San Pedro del Pinatar Regional Park (Murcia, Spain) based on user surveys
}

\author{
Diana Hernández Mármol ${ }^{*}$ \\ Gustavo A. Ballesteros Pelegrín ${ }^{2}$ (i) \\ Francisco Belmonte Serrato ${ }^{3}$ (i)
}

\section{Resumen}

El Parque Regional de las Salinas y Arenales de San Pedro del Pinatar es un humedal salino situado al norte de la restinga que cierra el Mar Menor (Región de Murcia). Forma parte de la Red Natura 2000, y está declarado Zona de Especial Conservación y Zona de Especial Protección para las Aves, además de ser un importante enclave de producción de sal y turístico. El objetivo de este trabajo es realizar una valoración preliminar de los servicios ecosistémicos del Parque Regional mediante la realización de encuestas pre-test a los usuarios del espacio protegido. Para ello se utilizaron métodos de preferencias declaradas: el método de Valoración Contingente y la Valoración por Experimentos de Elección. Se realizaron 262 encuestas pre-test a turistas entre agosto y diciembre de 2019, las cuáles orientaron la redacción de las encuestas finales. Además, se definieron los servicios ecosistémicos que ofrece el Parque Regional mediante el análisis de la Common International Classification of Ecosystem Services en su última versión V5.1, obteniendo 32 tipos de servicios ecosistémicos que serán valorados en las encuestas finales con cuatro opciones de respuesta.

Palabras clave: Encuestas; Servicios ecosistémicos; Valoración contingente; Valoración por experimentos de elección; Turismo; San Pedro del Pinatar.

\footnotetext{
Abstract

The Salinas y Arenales de San Pedro del Pinatar Regional Park is a saline wetland located in the north of the restinga of Mar Menor lagoon (Region of Murcia, southeast Spain). It is part of the Natura 2000 Network, and has been declared a special conservation area and special protection area, as well as being an important enclave for salt production and tourism. This study offers a preliminary assessment of the ecosystem services of this regional park through pre-test surveys answered by users of the protected area. The contingent valuation method, as well as the choice experiments method declared preference methods were used. Some 262 tourist pre-test surveys were conducted between August and December 2019, and these guided the writing of the final surveys. In addition, the ecosystem services offered by the regional park were defined by analysing the Common International Classification of Ecosystem Services in its latest version V5.1 (obtaining 32 types of ecosystem services that are evaluated in the final surveys with four response options).

Keywords: Surveys; Ecosystem services; Contingent Valuation; Assessment by choice experiments; Tourism; San Pedro del Pinatar.

1 Departamento de Geografía. Laboratorio de Geomorfología. Campus de la Merced. Universidad de Murcia, España. diana.h.m@um.es.

* Autora para correspondencia

2 Departamento de Geografía. Laboratorio de Geomorfología. Campus de la Merced. Universidad de Murcia, España. gabpl@um.es

3 Departamento de Geografía. Laboratorio de Geomorfología. Campus de la Merced. Universidad de Murcia, España. franbel@um.es 


\section{Introducción}

El área que hoy ocupa el Parque Regional de las Salinas y Arenales de San Pedro del Pinatar se ha conservado relativamente libre de la ocupación humana gracias a la actividad salinera. No se conoce con certeza desde cuando se ejerce esta actividad, pero se tiene constancia de que la extracción de sal se remonta hasta la época de la dominación cartaginesa en torno al año 200 a. C. Así, se mantuvo durante la romanización y, prácticamente de manera ininterrumpida, hasta nuestros días (Ballesteros y Fernández, 2013).

El espacio cuenta con diversas figuras de protección: en 1994 fue incluido en la Lista de Humedales de Importancia Internacional del Convenio RAMSAR y un año después en la Red de Áreas de Protección de la Fauna Silvestre. También ha sido declarado Parque Regional y designado como ZEPA y LIC, figuras por las que entró a formar parte de la Red Natura 2000 con la denominación de "Salinas y Arenales de San Pedro del Pinatar" (ES0000175). En el año 2001 se incluyó en la Lista de Zonas Especialmente Protegidas de Importancia para el Mediterráneo, y en 2019 fue declarado Zona de Especial Conservación e incluido en el Plan de Gestión Integral de los espacios protegidos del Mar Menor y la franja litoral mediterránea de la Región de Murcia. Sin embargo, el espacio sufre diversas amenazas, como son la pérdida de superficie del hábitat de nidificación de la gaviota de Audouin (Larus audouinii) y otras 6 especies del Anexo I de la Directiva Aves, la desconexión de una importante charca del circuito salinero (charca de Coterillo) de gran valor ecológico por su biodiversidad de invertebrados y en la que habitaba un pez endémico ibérico llamado fartet (Aphanius iberus), la erosión del sistema dunar de la playa de La Llana (de 3 kilómetros de extensión aproximadamente) y la invasión por especies exóticas de flora y fauna.

Este espacio natural protegido cuenta además con una gran afluencia turística, que se ha incrementado considerablemente desde el inicio de este siglo (Ballesteros, 2014b). Los datos indican un incremento del número visitantes (aproximadamente 130.000 más en el período comprendido entre 1999 y 2010) que acuden en época estival a las salinas para disfrutar del turismo de salud, pues los baños de lodos y arcillas son muy conocidos por sus beneficios terapéuticos, bactericidas, antisépticos y antiinflamatorios. Por otro lado, el Centro de Información para Visitantes 'Las Salinas' registró un incremento en más de 10.000 personas entre los años 2008 y 2018 (Dirección General de Medio Ambiente, 2014 y Oficina de Impulso Socioeconómico del Medio Ambiente, 2018), que solicitaban información sobre el espacio protegido y las actividades que desarrolla el Centro. En el año 2019 se realizó un conteo, enmarcado en la Acción D5 del Proyecto LIFE17 NAT/ES/000184 Conservación de los hábitats y aves acuáticas en el LIC y ZEPA ES0000175 "Salinas y Arenales de San Pedro del Pinatar" (LIFE SALINAS) denominada "Evaluación del impacto socio-económico y de los servicios de los ecosistemas", que estimó en 310.000 el número de visitantes anuales.

En el último medio siglo, el turismo ha demostrado ser un importante contribuyente al crecimiento económico (Fernández, López, Such, 2017), representando en el año 2018 un 12,3\% del PIB español según el último dato oficial para el año 2018 publicado por la Cuenta Satélite del Turismo en España (CSTE), a la par que también se evoluciona desde un turismo casi exclusivamente de sol y playa, a otros como el cultural, de naturaleza, deportivo o rural (Vizcaíno, 2015). Para Martínez Quintana (2017), turismo de naturaleza, desarrollo y turismo sostenible se encuentran directamente relacionados. A su vez surge el ecoturismo que, con multitud de acepciones, se puede concebir como aquel que se practica respetando el entorno y su población. Además, y según indica Ballesteros (2014a), el desarrollo sostenible en el Parque Regional de las Salinas y Arenales de San Pedro del Pinatar parece ser la única estrategia para la conservación de este enclave, siendo para ello necesario dar alternativas al turismo de sol y playa.

Aunque durante siglos la explotación salinera ha evitado la ocupación urbanística y propiciado el mantenimiento del humedal, son necesarias nuevas medidas de gestión ante diferentes modelos de turismo, pues el ecosistema se enfrenta a nuevos retos de supervivencia: cambio climático, turismo no gestionado que pueda sobrepasar la capacidad de carga, etc. Además, se considera necesario revisar los numerosos servicios ecosistémicos que el espacio protegido proporciona, aspecto objeto de estudio del Proyecto LIFE SALINAS.

Se define servicio ecosistémico (Millennium Assessment, 2003, 2005) como el beneficio que las personas reciben de los ecosistemas. En el año 2000, la preocupación por las altas cifras de hambre, pobreza, educación y enfermedades, así como por la degradación de los ecosistemas, impulsó el nacimiento de la Evaluación de los Ecosistemas del Milenio (Montes y Sala, 2007). Dicho proyecto fue encargado por 
Kofi Annan, Secretario General de las Naciones Unidas, con el objetivo de analizar las consecuencias del cambio de los ecosistemas para el bienestar humano. Se trata de una iniciativa común de múltiples organismos que persigue proporcionar a los decisores y al público en general, información científica pertinente sobre la situación de los ecosistemas, las consecuencias de sus cambios y las posibilidades de respuesta. Desde sus inicios, la Evaluación de Ecosistemas del Milenio clasificó los servicios ecosistémicos distinguiendo entre los de aprovisionamiento, regulación, servicios culturales y de apoyo (Millennium Assessment, 2003, 2005). En el desarrollo de la Evaluación de los Ecosistemas del Milenio se vio necesario clarificar un marco conceptual que estableciera las complejas interacciones en la explotación de los ecosistemas y que explicara como los cambios en los servicios ecosistémicos afectan al bienestar humano a diferentes escalas (local, regional y global) (Figura 1):

Figura 1. Marco conceptual de la Evaluación de los Ecosistemas del Milenio

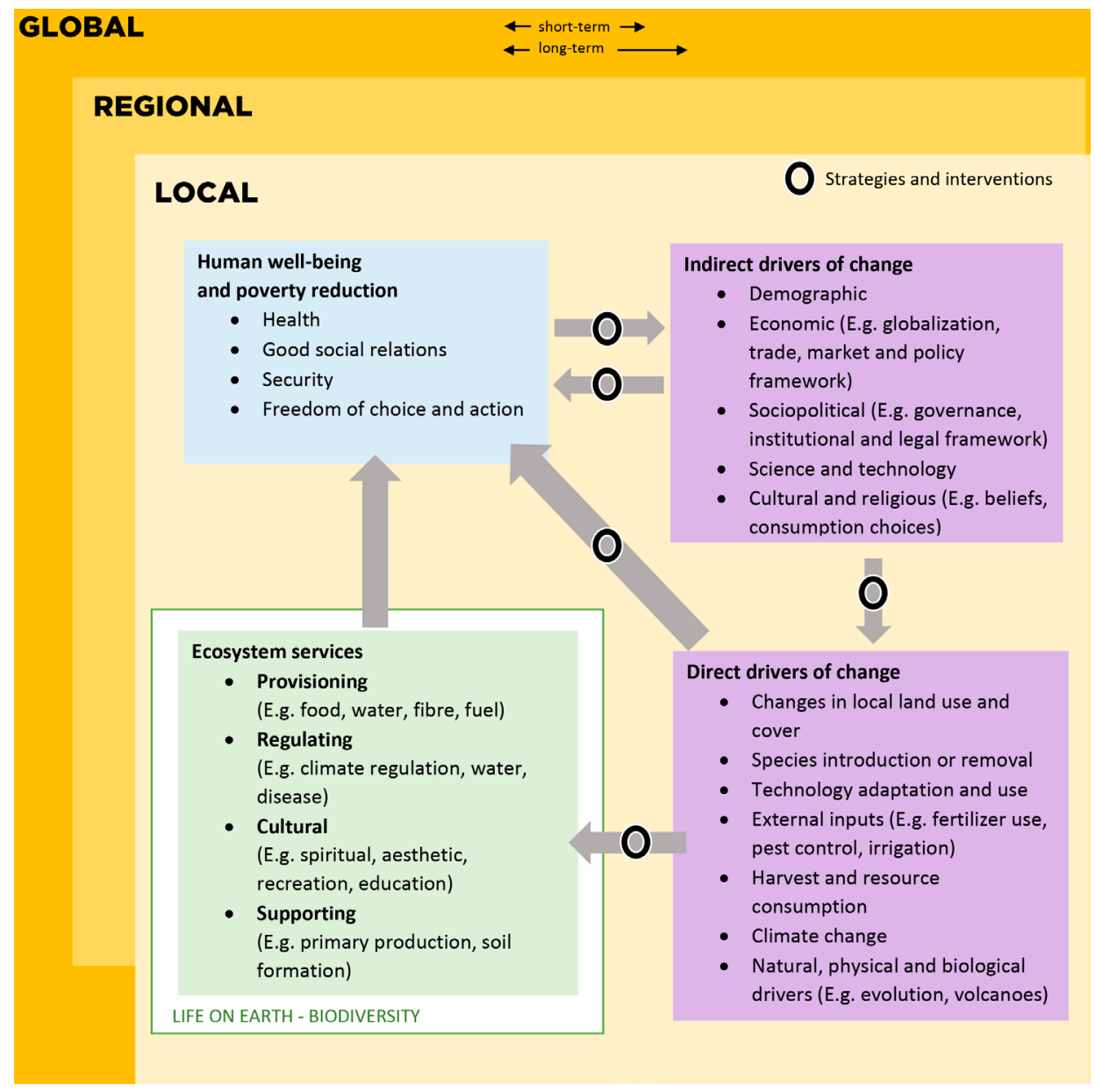

Fuente: Millennium Assessment, 2005

El uso real de un bien o servicio proporciona beneficios (nutrición, salud, placer, etc.) que a su vez pueden valorarse en términos económicos y monetarios (De Groot, Alkemade, Braat, Hein y Willemen, 2009). Sin embargo, el valor social de los servicios ecosistémicos derivados de la naturaleza y que satisfacen algunas necesidades para el bienestar humano, no tiene representación en los mercados financieros. Esto presenta serias dificultades para reflejarlo en términos económicos de cara a la creación de estrategias por parte de políticos y gestores. Por este motivo, la ciencia económica ha venido desarrollando métodos específicos de valoración de bienes y servicios ambientales (Bengochea, Fuertes, del Saz y 2003), permitiendo valorar económicamente el cambio en el bienestar del individuo tras el cambio en la cantidad o calidad de un bien ambiental.

En el contexto del estudio de los servicios ecosistémicos del Parque Regional de las Salinas y Arenales de San Pedro del Pinatar, los objetivos de este trabajo son: a) el análisis de las metodologías de valoración 
económica ambiental basadas en métodos de preferencias a través de mercados hipotéticos; b) el análisis de la disposición a pagar por los servicios ecosistémicos o principales objetivos de conservación del Proyecto LIFE SALINAS a través de los resultados de las 262 encuestas pre-test realizadas a turistas, lo que orientará el diseño de la encuesta final; c) la identificación y caracterización de los servicios ecosistémicos en el ámbito de estudio, por lo que se ha realizado una completa revisión de los mismos siguiendo la clasificación CICES (Common International Classification of Ecosystem Services).

\section{Metodología}

\section{1. Área de muestreo}

El Parque Regional de las Salinas y Arenales de San Pedro del Pinatar se localiza en la zona más septentrional de la Región de Murcia, limitando al norte con la provincia de Alicante, al este con el Mar Mediterráneo, al oeste con la laguna del Mar Menor y al sur con Las Encañizadas, un canal natural de intercambio de agua entre el Mar Mediterráneo y el Mar Menor (Figura 2). Tiene una extensión de 856 ha, de las cuales 496 ha se dedican a la explotación salinera.

Figura 2. Delimitación del Parque Regional de las Salinas y Arenales de San Pedro del Pinatar

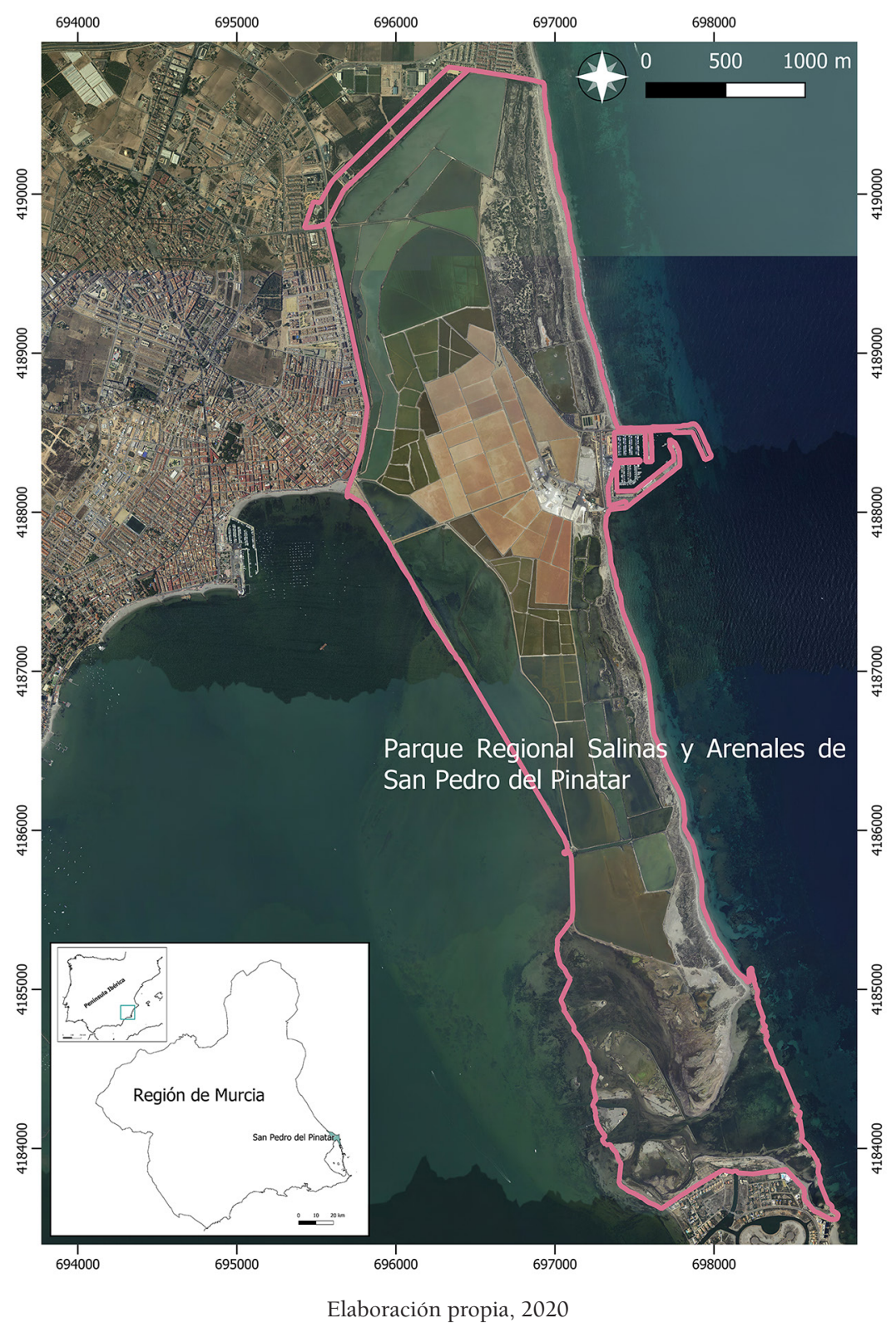


En el espacio protegido se puede realizar un recorrido perimetral con una distancia aproximada de 12 kilómetros, quedando 6 zonas accesibles para los turistas: Curva de la Culebra, Playa de La Torre Derribada, Aparcamiento de Coterillo, Aparcamiento del Puerto, Playa de La Llana y Camino de la Mota (Figura 3).

Figura 3. Zonas de acceso para los turistas al Parque Regional de las Salinas y Arenales de San Pedro del Pinatar

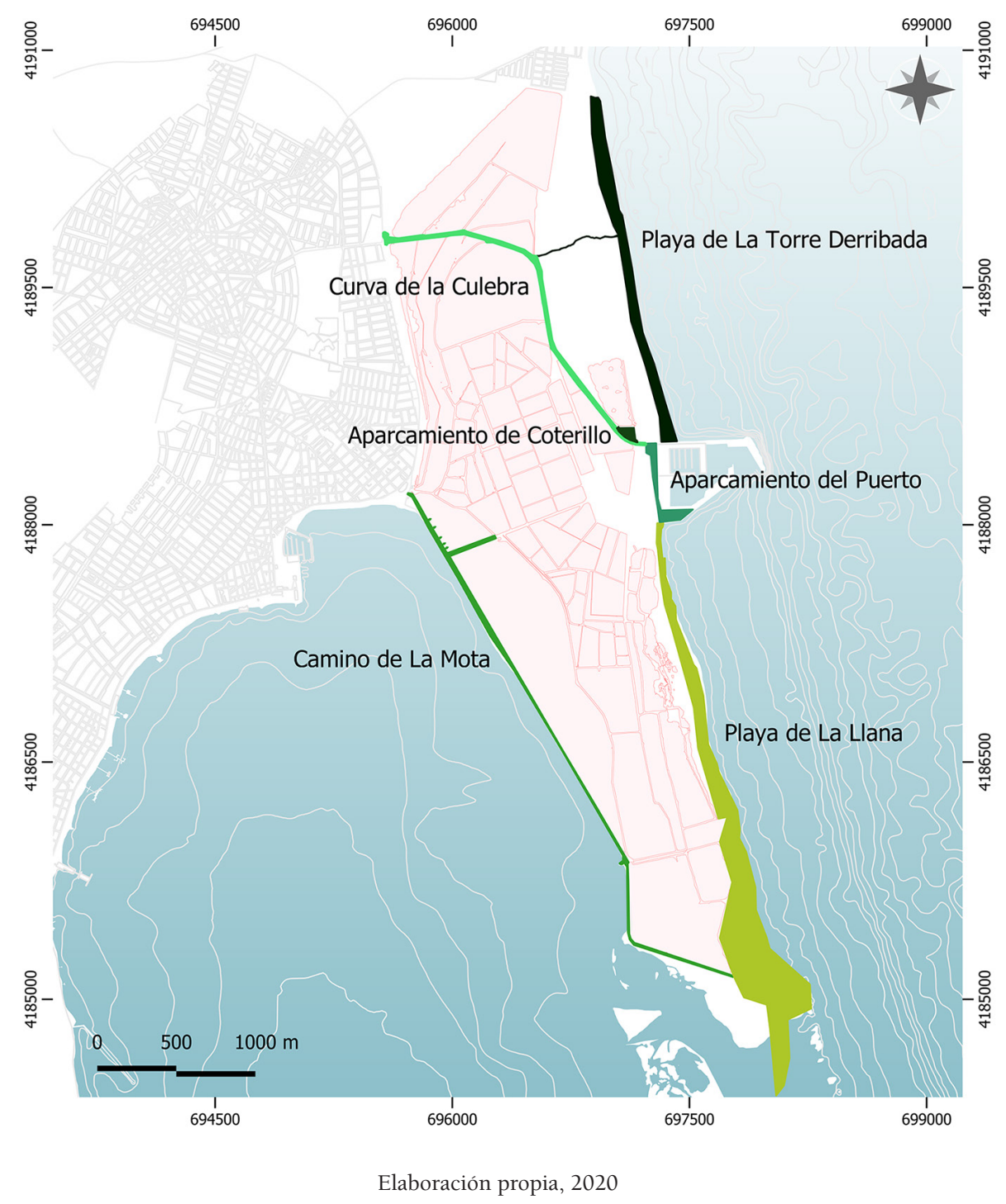

\subsection{Estudio de los métodos de valoración para la elaboración de las encuestas}

El beneficio que recibe la sociedad gracias a los servicios ecosistémicos se puede reflejar en valores que se pueden clasificar como valores de uso (aprovechamiento actual) y valores de no uso (que pueden ser de opción cuando existe la posibilidad de un disfrute futuro, o de existencia cuando se le da valor por el simple hecho de existir) (Maldonado y Cuervo, 2016).

Para las valoraciones económicas se utilizaron dos métodos: el método de Valoración Contingente, que mide la disponibilidad a pagar por el acceso a un bien; y el método de Experimentos de Elección donde el encuestado elige la alternativa que más le satisface. Con las encuestas para los empresarios locales y técnicos de las distintas administraciones se obtendrán datos sobre el impacto económico del Proyecto LIFE SALINAS, tales como la inversión realizada, las tasas de ocupación, la estacionalidad, etc.

Ambas valoraciones han sido ampliamente aplicadas en la valoración de bienes y servicios ambientales y se clasifican como métodos directos o de preferencias declaradas, ya que se utilizan en encuestas 
para solicitar a los entrevistados que indiquen directamente su disposición a pagar (DAP) por la mejora de un bien, o su disposición a aceptar (DAA) por un cambio hipotético en la cantidad o la calidad de bienes y servicios ambientales (Sánchez, 2013), creando un mercado hipotético donde se reflejan las preferencias por un bien o servicio (Maldonado y Cuervo, 2016). Aunque durante mucho tiempo la Valoración Contingente ha sido una de las metodologías más empleadas para valorar bienes y servicios ambientales de no mercado (León y Vásquez-Polo, 2000; Welsch y Uhling, 2009), los Experimentos de Elección dan un enfoque más útil desde una perspectiva de gestión y política, ya que no se centra en la ganancia o pérdida de un bien o en el cambio que pueda producirse en él como ocurre en la Valoración Contingente, sino que descompone el bien en sus atributos para obtener una mejor comprensión del valor total (Vázquez y Prada, 2003). De esta forma, se obtiene la estructura jerárquica de preferencias del participante, que pueden ser aplicadas en políticas de gestión del espacio (Martínez-Paz, Martínez-Carrasco, Estéve, Fructuoso y Navalón, 2008).

\subsection{Valoración contingente}

En la valoración económica ambiental el objetivo es establecer un valor monetario cuando una persona o colectivo gana o pierde bienestar al ser mejorado o dañado un activo ambiental (Romero, 1997). No existen mercados reales para los bienes ambientales, pues su precio es incalculable, y solamente se pueden valorar a través de la creación de mercados hipotéticos que nacen dentro del campo de la valoración ambiental en la ciencia económica (Grajales, 2005), y donde se tratan problemáticas como la asignación de los recursos naturales, la valoración económica de los cambios ambientales, las externalidades y las preferencias sociales sobre la preservación de un bien o servicio ambiental. Con estos cálculos no se pretende obtener un precio de venta, sino un indicador monetario del activo valorado, o, dicho de otro modo, un indicador de lo que se estaría dispuesto a renunciar para mantener el activo ambiental (Alcón y López, 2017)

En definitiva, este tipo de cálculo consiste en valorar algo que puede o no suceder (contingente), midiendo económicamente como cambiaría el bienestar del sujeto que realiza la encuesta al darse un cambio a mejor o peor en la calidad o cantidad de un bien o servicio de la naturaleza, asumiendo que carece de mercado donde poder incluirlo. Llevado a la práctica, se realiza a través de un cuestionario donde se simula un mercado hipotético para el bien, en el cual la persona que responde indica su disposición a pagar por mantener el bien en su estado actual o su disposición a aceptar una compensación económica por el perjuicio a dicho bien (Bishop y Heberlein, 1979). Puesto que la definición de Valoración Contingente implica un cambio en el bien que se quiere evaluar, se suele emplear este método para espacios naturales que tienen una función de recreo para la población humana.

Lo que hace de la Valoración Contingente un método más aceptado que otros es, que aunque el encuestado no haya visitado un determinado espacio natural y solo conociendo sus valores medioambientales de forma teórica, es capaz de darle un valor, pues cabe la posibilidad de que algún día pueda visitarlo, o quizá valore que puedan visitarlo futuras generaciones, lo cual le reporta un beneficio por el que está hipotéticamente dispuesto a pagar cuando se le realiza la encuesta.

Según Azqueta (1994), es necesaria una estructura a seguir para la Valoración Contingente, de modo que en primer lugar se le den al encuestado las herramientas necesarias para conocer el bien que se va a evaluar. En segundo lugar, se exponen los cambios que se van a realizar, de calidad o de cantidad, preguntando también cómo sería el modo de pago (impuestos o tasas al mejorar el bien, compensación al empeorar). Por último, es necesario conocer los datos socioeconómicos del encuestado (ingresos, profesión, etc.) para poder tener una mejor comprensión de su respuesta.

Este método presenta, como todos, algunas ventajas e inconvenientes (Leal-Rojas, 2005). Por una parte, es cierto que el encuestado puede valorar algo que hasta ese momento no conocía, dándose el llamado valor de opción, es decir, valorar algo que se puede disfrutar o no más adelante, pensando también en próximas generaciones. Además, en este método se da la valoración de no uso, es decir, que en el momento en el que es entrevistado, ha conocido el bien, sabe que existe, y aunque no tenga intención de disfrutarlo, lo valora. Sin embargo este método también presenta desventajas, ya que no deja de ser subjetivo y es natural que se den respuestas exageradas, provocando sesgos en el vehículo de pago, la percepción del contexto y la información suministrada al encuestado, aspectos que deben ser tenidos en cuenta para asegurar que no haya sobreestimación de los valores (Riera, 1994; Hernández, 2010). 
Teniendo en cuenta todo lo anterior, se plantea el apartado de la encuesta donde se tiene en cuenta el método de Valoración Contingente con las opciones de pagar o ser compensado, pudiéndose formular entonces la pregunta de cuatro formas distintas según se quiera obtener una respuesta de forma abierta (A) o de forma cerrada (C):

- Opción 1. DAP: (A) ¿Qué pagaría usted por evitar un perjuicio al bien? (C) ¿Pagaría usted la cantidad X por evitar un perjuicio al bien?

- Opción 2. DAP: (A) ¿Qué pagaría usted por mejorar el bien? (C) ¿Pagaría usted la cantidad X por mejorar el bien?

- Opción 3. DAA: (A) ¿Qué cantidad de dinero sería necesaria para compensarle por un perjuicio al bien? (C) ¿Por la cantidad X de dinero quedaría usted compensado por el perjuicio al bien?

- Opción 4. DAA: (A) ¿Qué cantidad de dinero sería necesaria para compensarle por no mejorar un bien? (C) ¿Por la cantidad X de dinero quedaría usted compensado por no mejorar el bien?

Después de obtener los valores numéricos en la forma abierta (A), se hace una media de todas las disposiciones a pagar, hayamos elegido las opciones 1 y 3 (máxima cantidad de dinero para evitar o ser compensado por un perjuicio al bien) o 2 y 4 (máxima cantidad de dinero por mejorar o no el bien). La media nos dará un valor global de los resultados respecto al tamaño de la población escogida, interviniendo de forma directa en el resultado final (Riera, 1994).

En la forma cerrada, solo puede elegir entre dos respuestas (si y no) y se calcula la proporción de los resultados, pudiendo ser representados para obtener una visión gráfica de los mismos. También se pueden obtener resultados numéricos: si la respuesta cerrada a la pregunta fue $\mathrm{Si}$, se puntúa con 1 ; siendo 0 si la respuesta fue No (Alcón y López, 2017).

\subsection{Experimentos de Elección. Modalidad: Ranking Contingente}

Según Martínez-Carrasco, Martínez-Paz y Esteve (2012), la valoración de espacios naturales a través de los Experimentos de Elección se ha venido utilizando en España a partir de finales de la década de los noventa. También se ha trabajado con Experimentos de Elección en la Región de Murcia, por ejemplo en el Mar Menor (Segado y Castro, 2003; Perni, Martínez-Carrasco y Martínez-Paz, 2011; Martínez-Paz et al, 2015) o en otros Parque Regionales, como Cabo Cope y Puntas de Calnegre (Martínez-Paz, Esteve-Selma y Belmonte, 2007); Sierra Espuña (Martínez-Aedo, Páez y López, 2008; Martínez-Paz, Perni y Almansa, 2012) o el Parque Regional de Calblanque, Monte de las Cenizas y Peña del Águila (Martínez-Carrasco et al., 2012).

En este método, en vez de preguntar al participante cuál es su disposición a pagar, el bien se desglosa en todos sus atributos, permitiendo que el participante valore cada uno de ellos por separado, ordenando además las alternativas elegidas (Ranking Contingente). Los Experimentos de Elección están basados en la teoría del valor, donde la suma de las utilidades de sus atributos proporcionará al participante el valor total del bien; y en la teoría de la utilidad aleatoria, donde elige la alternativa que le reporta mayor utilidad (Alcón y López, 2017). De forma práctica, consiste en crear un cuadro con todos los atributos del bien, clasificados por categorías o bloques, y se le pregunta a la persona entrevistada para que exprese sus preferencias en el consumo del bien (Vázquez y Prada, 2003). La elección realizada (Espinal y Gómez, 2011) indica una preferencia por esos atributos sobre los demás, permitiendo transformar las respuestas en magnitudes monetarias. De todas las combinaciones ofertadas, se consigue conocer la alternativa más valorada por el encuestado (Martínez-Carrasco et al., 2012).

Finalmente, es necesario definir qué se va a valorar respecto a las prioridades sociales en estas encuestas, y qué líneas de atributos se van a considerar.

\subsection{Diseño de la encuesta preliminar o pre-test.}

Se realizó una primera selección y valoración de los servicios ecosistémicos o amenazas sobre los que actúa el Proyecto LIFE SALINAS mediante encuestas pre-test a visitantes del Parque Regional entre agosto y diciembre de 2019. La encuesta pre-test tenía un doble objetivo: por un lado, conocer qué atributos son los más valorados por los encuestados; y en segundo lugar, conocer la DAP para aplicar el resultado medio en la encuesta final. 
Es importante señalar que previo a la encuesta se informó a los participantes sobre el Proyecto LIFE SALINAS, el objeto del estudio y los atributos de los aspectos a valorar. Como principales atributos a valorar se tomaron los objetivos generales del Proyecto organizados en bloques de actuación, tal y como se detalla en la Figura 4:

Figura 4. Objetivos del Proyecto LIFE SALINAS tomados como atributos para la valoración por Experimentos de Elección

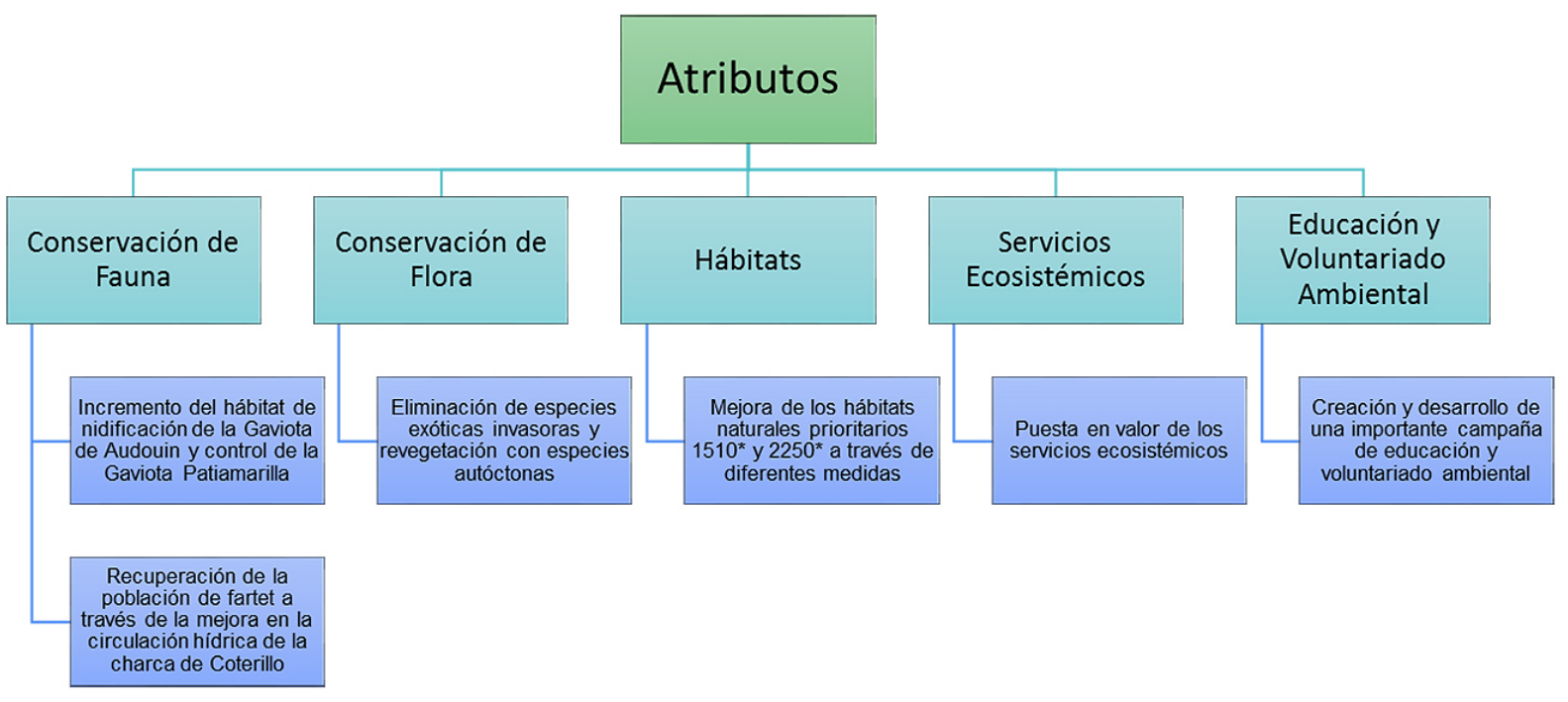

Elaboración propia, 2020

Como alternativas se eligió el mantenimiento de la situación actual frente a la situación de mejora, subdividida esta opción en 5 componentes: una elección sin aportación y cuatro opciones con distintos niveles de aportación económica. La encuesta pre-test diseñada y empleada fue la siguiente (Figura 5):

Figura 5. Encuesta pre-test realizada a los visitantes del Parque Regional de las Salinas y Arenales de San Pedro del Pinatar
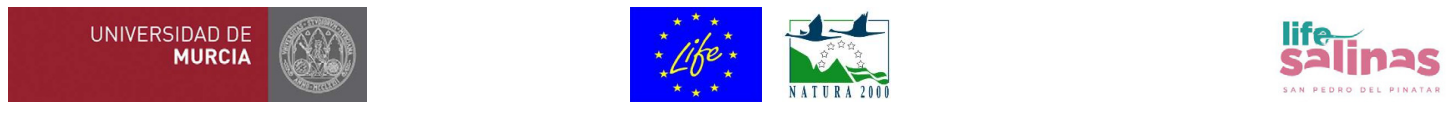

Encuesta piloto sobre el Parque Regional Salinas y Arenales de San Pedro del Pinatar en el marco del Proyecto LIFE Salinas (LIFE17 NAT/ES/000184) realizada por la Universidad de Murcia. Proyecto LIFE Conservación de los hábitats y aves acuáticas en el LIC y ZEPA ES0000175 "Salinas y Arenales de San Pedro del Pinatar" Más información en www.lifesalinas.es La encuesta es anónima y las respuestas hipotéticas

\begin{tabular}{|c|c|c|c|c|c|c|}
\hline Alternativa & \multirow{2}{*}{ Situación Actual } & \multirow{2}{*}{$\begin{array}{l}\text { Mejora, pero NO estoy } \\
\text { dispuesto/a a hacer una } \\
\text { aportación }\end{array}$} & \multicolumn{4}{|c|}{ ¿Qué aportaría por la mejora? } \\
\hline Atributos & & & $<5 €$ & $>5 €$ & $10-20 €$ & $>20 €$ \\
\hline 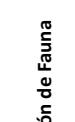 & $\begin{array}{l}\text { Gaviota patiamarilita oportunista y } \\
\text { depredadora }\end{array}$ & $\begin{array}{l}\text { Mejora del hábitat de Gaviota } \\
\text { de Audouin }\end{array}$ & & & & \\
\hline & $\begin{array}{l}\text { Pez endémico ibérico en peligro de } \\
\text { extinción }\end{array}$ & $\begin{array}{c}\text { Mejora de la circulación de la } \\
\text { charca de Coterillo }\end{array}$ & & & & \\
\hline 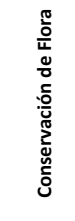 & 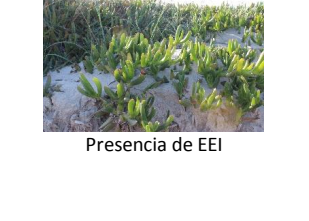 & $\begin{array}{l}\text { Eliminación de EEl, } \\
\text { revegetacicion con Especies } \\
\text { autóctonas }\end{array}$ & & & & \\
\hline
\end{tabular}




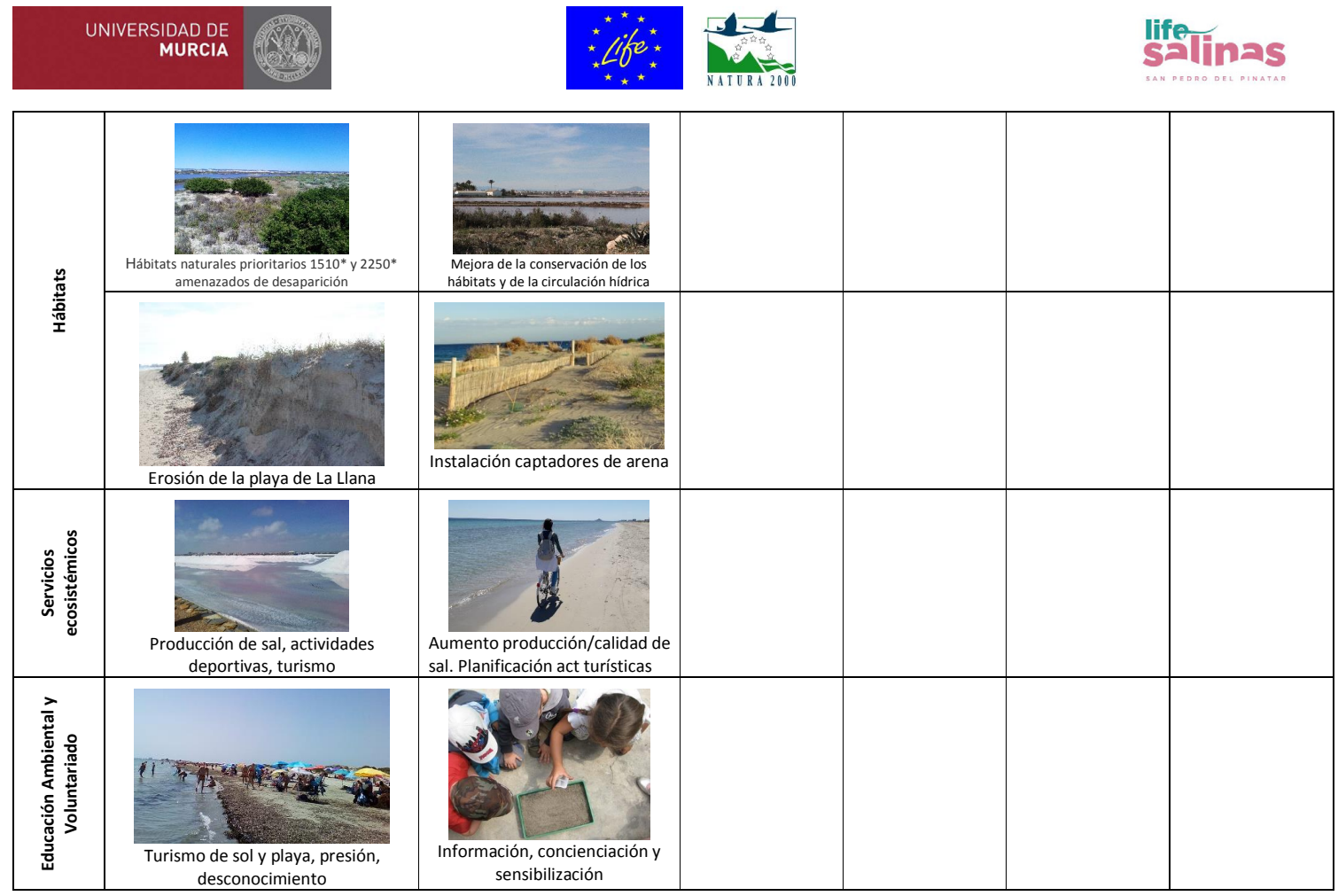

Elaboración propia, 2020

Los bienes Conservación de fauna, Conservación de flora, Hábitats, Servicios ecosistémicos, Educación y Voluntariado Ambiental (productos o servicios que ofrece el Parque Regional) han sido desglosados en 7 atributos específicos, permitiendo al participante de la encuesta que valore cada uno de ellos por separado, aplicando la valoración por experimentos de elección. Además, realiza una valoración contingente, pues comparamos la situación actual con una que podría darse en la hipotética mejora por su aportación.

El universo poblacional son los turistas y usuarios del espacio protegido. De acuerdo con los conteos realizados en 2019 (dos conteos mensuales: uno en día laboral y otro en día festivo), el Parque Regional acoge aproximadamente a 310.000 visitantes al año. Por lo tanto, el número de encuestas será de 1.303 al inicio del proyecto y 1.303 al final, con un margen de error del 3\% para un nivel de confianza del $97 \%$.

Dado que se desean obtener los resultados de 2.600 encuestas finales, se consideró la realización del 10\% de las mismas, es decir, la realización de 260 encuestas pre-test. La realización de encuestas pre-test contribuye a identificar los valores a utilizar en los ejercicios de valoración de la encuesta final. Se eligieron cifras económicas relativamente elevadas (aportación de menos de $5 €$, más de $5 €$, entre 10 y $20 €$ y más de $20 €$ ), de forma que la encuesta pre-test sirviera para aproximar los valores en la encuesta final. La utilidad de la encuesta pre-test reside no solo en mejorar las respuestas sino en ajustar además el lenguaje de las mismas (Maldonado y Cuervo, 2016). Después de varios ensayos se optó por la respuesta de forma cerrada para la Valoración Contingente, pues los encuestados divagaban y aludían al NS/NC.

\subsection{Servicios Ecosistémicos: la clasificación CICES}

Existe una clasificación internacional de los servicios ecosistémicos (Common International Classification of Ecosystem Services, CICES) que evolucionó a raíz del trabajo en contabilidad medioambiental encargado por la Agencia Europea del Medio Ambiente. Apoya su contribución a la revisión del Sistema de Contabilidad Económica Ambiental (SEEA) que actualmente está siendo dirigido por la División de Estadística de las Naciones Unidas (UNSD). 
CICES busca identificar los servicios ecosistémicos finales que se vinculan a los bienes y beneficios que las personas valoran, siendo utilizado para el mapeo y evolución de los servicios a escala europea, cumpliendo así con los compromisos asumidos en virtud de la Acción 5 de la Estrategia de la UE sobre Biodiversidad para 2020 (Maes et al., 2018). CICES es además un sistema de clasificación de referencia (Haines-Young y Potschin, 2018), pues permite, mediante un código, su traducción a otros sistemas de clasificación de servicios ecosistémicos, como los utilizados por la Evaluación de los Ecosistemas del Milenio (MA) y La Economía de los Ecosistemas y la Biodiversidad (TEEB por sus siglas en inglés). Por este motivo, la clasificación CICES se eligió para nuestro estudio, siendo utilizada para la evaluación de los servicios ecosistémicos por parte de los usuarios del Parque Regional.

Para lo que se considera como 'servicios finales del ecosistema', CICES ha diferenciado hasta ahora 90 servicios ecosistémicos organizados en una estructura jerárquica de cinco niveles, donde cada nivel es progresivamente más detallado y específico: Sección, División, Grupo, Clase y Tipo de clase. Esta clasificación de niveles refleja una 'taxonomía' en la que los elementos de un mismo Grupo o Clase son conceptualmente más similares entre sí que otros servicios ecosistémicos (Haines-Young y Potschin, 2018).

La Sección clasifica los servicios del ecosistema en tres categorías y a su vez, realiza una diferenciación entre servicios bióticos y abióticos. La nueva versión CICES V5.1 permite por lo tanto seleccionar solo aquellos servicios ecosistémicos que dependen de sistemas vivos (bióticos) o incluir las partes 'no vivas' de los ecosistemas y que también pueden contribuir al bienestar humano (abióticos). Esta clasificación en la Sección puede ser difícil de comprender en la práctica, sin embargo CICES incluye 'agua' en abiótico razonando que los ciclos hidrológicos son impulsados principalmente por procesos geofísicos.

Para determinar los servicios ecosistémicos que ofrece el espacio protegido, se envió la clasificación de los 90 servicios que vienen descritos en la clasificación CICES a todos los miembros del equipo LIFE SALINAS y se les pidió que eligieran aquellos servicios que consideraban que pudiera ofrecer el Parque Regional. Cabe destacar que el equipo que integra el Proyecto LIFE SALINAS está formado por técnicos en medio ambiente, profesores de universidad, personas relacionadas con la gestión del Parque Regional y personal técnico de la empresa salinera.

\section{Resultados}

\subsection{Resultados de las encuestas preliminares}

Los resultados de las encuestas pre-test sirvieron para el diseño y evaluación del impacto económico y social del Proyecto LIFE SALINAS en las encuestas finales. Se obtuvieron los resultados de un total de 262 encuestas pre-test (Figura 6), de las que 156 se realizaron mediante encuesta personal y 106 a través de encuesta online.

La opción que obtuvo un mayor porcentaje de respuesta, con mucha diferencia sobre las demás para los 7 atributos fue la B, donde los participantes estaban de acuerdo con que se mejore la situación actual, pero no estaban dispuestos a realizar ninguna aportación económica hipotética. La segunda opción más elegida fue la de aquellos que optaban por mejorar la situación y estarían dispuestos a aportar hasta 5 euros al año como contribución económica (opción C).

En Martínez-Paz et al. (2008) se establece una cifra como valor central de la subasta, alrededor de la cual se fijan otros valores. Dado que el resultado en nuestro estudio fue de 5 euros para todos los atributos, se estableció esta cifra como valor central de la subasta para la Valoración Contingente, fijándose alrededor de la misma otros dos valores monetarios: 2,5 y 7,5 euros. De esta forma se establecen 4 opciones de respuesta para las valoraciones económicas: (a) Nada, (b) Realizaría una aportación de 2,5 €/año, (c) Realizaría una aportación de $5 € /$ año y (d) Realizaría una aportación de 7,5 €/año. El planteamiento de esta valoración se muestra en el siguiente apartado, donde se analizan los servicios ecosistémicos considerados para el Parque Regional de las Salinas y Arenales de San Pedro del Pinatar y cómo se realizaría la valoración económica. 
Figura 6. Porcentaje de respuestas en las 262 encuestas pre-test realizadas

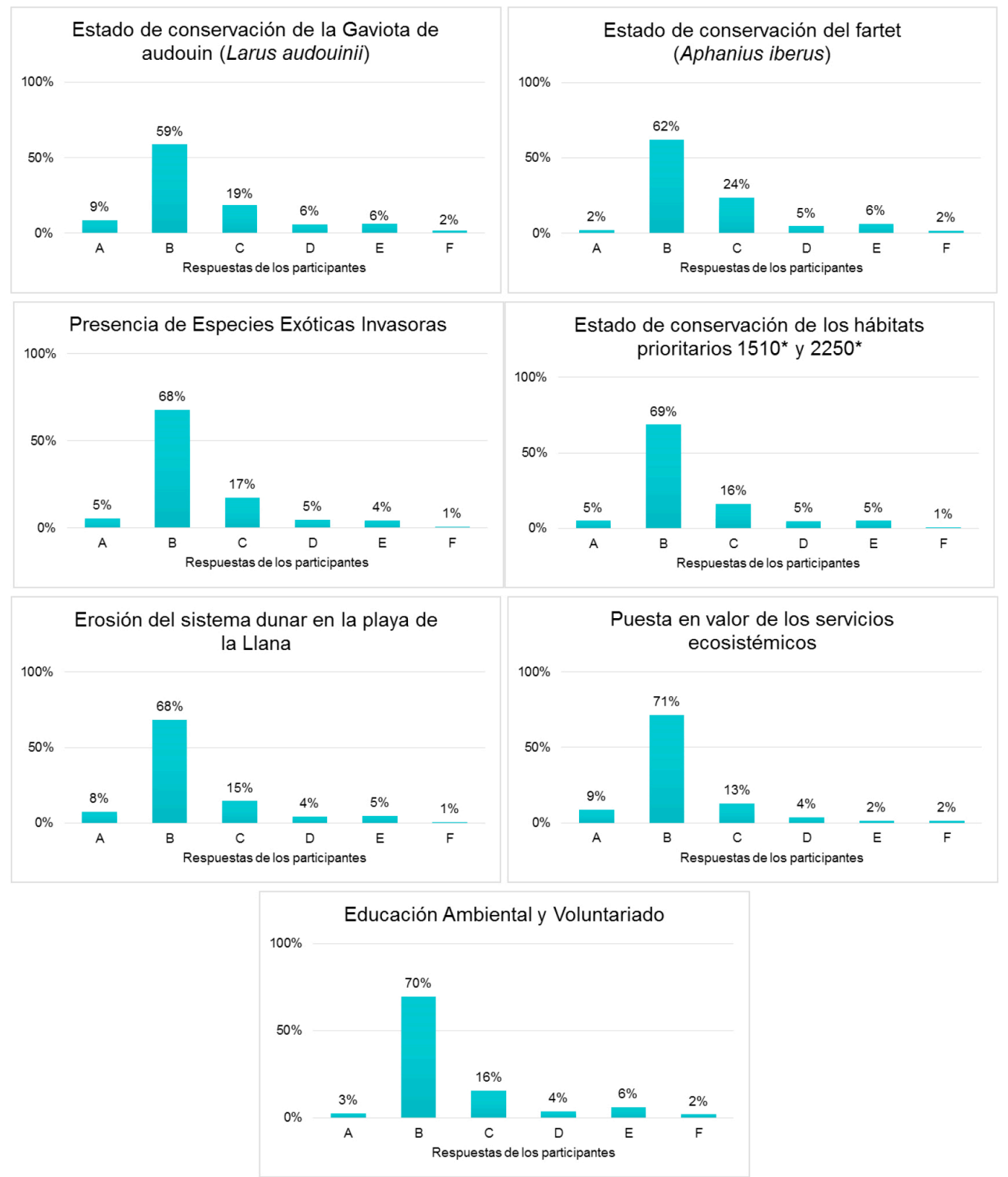

Las respuestas de los entrevistados fueron: Elijo la situación actual (A), Elijo una mejora del estado de conservación pero no estoy dispuesto/a a hacer una aportación (B), Elijo mejorar la situación aportando menos de 5 €/año (C), Elijo mejorar la situación aportando más de $5 € /$ año (D), Elijo mejorar la situación aportando entre 10 y 20 €/año (E), Elijo mejorar la situación con la aportación que yo elija, siendo superior a $20 € /$ año (F).

Elaboración propia, 2020

\subsection{Identificación y valoración de los servicios ecosistémicos en el diseño de la encuesta final}

Tras la evaluación de los 90 servicios ecosistémicos disponibles en la última versión CICES V5.1 por parte de todos los miembros que integran el equipo LIFE SALINAS, se llegó a la conclusión de que el espacio protegido ofrece al menos 32, y que el Proyecto LIFE SALINAS actúa (de forma directa o indirecta) o puede evaluar de alguna forma 31 de ellos a través de 11 acciones. A continuación, se muestran los servicios ecosistémicos consensuados por categorías y según sean bióticos o abióticos.

En la Tabla 1 se muestran los servicios ecosistémicos que pertenecen a la Sección Aprovisionamiento (biótico): 
Tabla 1. Servicios de aprovisionamiento para aquellos ecosistemas que dependen de organismos vivos

\begin{tabular}{|c|c|c|c|c|c|c|}
\hline Sección & División & Grupo & Clase & $\begin{array}{l}\text { Código } \\
\text { CICES } \\
\text { V5.1 }\end{array}$ & Servicio Ecosistémico & $\begin{array}{l}\text { Acción } \\
\text { LIFE }\end{array}$ \\
\hline \multirow{2}{*}{ 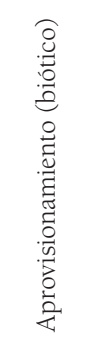 } & Biomasa & $\begin{array}{c}\text { Animales (terrestres } \\
\text { y acuáticos) para la } \\
\text { nutrición, materiales } \\
\text { o energía }\end{array}$ & $\begin{array}{l}\text { Animales (terrestres } \\
\text { y acuáticos) utilizados } \\
\text { con fines nutricionales }\end{array}$ & 1.1 .6 .1 & $\begin{array}{l}\text { Pesca, alimentación } \\
\text { de animales }\end{array}$ & $\mathrm{C} 2$ \\
\hline & $\begin{array}{l}\text { Material genético } \\
\text { de toda la biota } \\
\text { (incluidas las } \\
\text { semillas, esporas o } \\
\text { la producción de } \\
\text { gametos) }\end{array}$ & $\begin{array}{c}\text { Material genético } \\
\text { de plantas, algas } \\
\text { u hongos }\end{array}$ & $\begin{array}{l}\text { Semillas, esporas y otros } \\
\text { materiales vegetales } \\
\text { recolectados para } \\
\text { mantener } \\
\text { o establecer una } \\
\text { población }\end{array}$ & 1.2 .1 .1 & $\begin{array}{l}\text { Recolección } \\
\text { de semillas }\end{array}$ & $\mathrm{C} 4$ \\
\hline
\end{tabular}

Acciones del proyecto LIFE SALINAS relacionadas: C2. Infraestructura verde: conexión de la charca de Coterillo con el circuito salinero, C4. Revegetación con especies autóctonas en las dunas de la playa de Coterillo.

Elaboración propia

El primer servicio ecosistémico que se describe es el de la pesca, un recurso necesario para la alimentación y una de las actividades económicas más antiguas para muchos territorios del mundo. La charca de Coterillo albergaba especies de peces comerciales antes de su colmatación por sales y nutrientes. La acción C2 conectará esta charca con el circuito salinero, introduciendo agua y generando una circulación hídrica que permitirá la recolonización de dichas especies.

La vegetación autóctona del Parque Regional de las Salinas y Arenales de San Pedro del Pinatar ha permitido y permite la recolección de semillas, cuya reproducción se realizará en vivero. En el Proyecto LIFE SALINAS, está prevista la repoblación de 2 hectáreas de ecosistemas dunares con un total de 16.000 plantones gracias a la acción C4.

En la siguiente tabla (Tabla 2) se muestran los servicios ecosistémicos que pertenecen a la Sección Aprovisionamiento (abiótico):

Tabla 2. Servicios de aprovisionamiento para aquellos ecosistemas que no dependen de organismos vivos

\begin{tabular}{|c|c|c|c|c|c|c|}
\hline Sección & División & Grupo & Clase & $\begin{array}{l}\text { Código } \\
\text { CICES } \\
\text { V5.1 }\end{array}$ & Servicio Ecosistémico & $\begin{array}{l}\text { Acción } \\
\text { LIFE }\end{array}$ \\
\hline \multirow{2}{*}{ 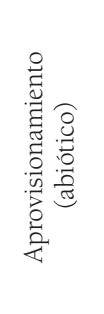 } & \multirow{2}{*}{$\begin{array}{l}\text { Productos del } \\
\text { ecosistema abiótico } \\
\text { natural no acuoso }\end{array}$} & $\begin{array}{c}\text { Sustancias minerales } \\
\text { utilizadas para nutrición, } \\
\text { materiales } \\
\text { o energía }\end{array}$ & $\begin{array}{l}\text { Sustancias minerales } \\
\text { utilizadas con fines } \\
\text { nutricionales }\end{array}$ & 4.3.1.1 & Valor nutricional (sal) & $\begin{array}{l}\text { C1, D5, } \\
\text { E3 }\end{array}$ \\
\hline & & $\begin{array}{l}\text { Sustancias no minerales } \\
\text { o propiedades del } \\
\text { ecosistema utilizadas para } \\
\text { nutrición, materiales o } \\
\text { energía }\end{array}$ & $\begin{array}{l}\text { Sustancias no minerales } \\
\text { o propiedades de los } \\
\text { ecosistemas utilizados } \\
\text { para fines nutricionales }\end{array}$ & 4.3 .2 .1 & $\begin{array}{l}\text { Valor nutricional } \\
\text { (Vitamina D) }\end{array}$ & $\mathrm{C} 3$ \\
\hline
\end{tabular}

Acciones del proyecto LIFE SALINAS relacionadas: C1. Infraestructura verde: adecuación de motas con material autóctono del sustrato salinero, C3. Estabilización y refuerzo del ecosistema dunar de la playa de la Llana, D5. Evaluación del impacto socioeconómico y de los servicios de los ecosistemas, E3. Diseño e implementación de un certificado de calidad y protección ambiental para la sal de las salinas de la Red Natura 2000

Elaboración propia

La sal es un recurso mineral utilizado para la nutrición desde hace miles de años. El espacio de las salinas de San Pedro del Pinatar ha sido utilizado para su extracción desde hace unos 200 años a. C. (Ballesteros y Fernández, 2013) hasta nuestros días. Con la acción Cl se aumentará en 1.800 metros lineales la superficie de motas, incrementando el recorrido que realiza la salmuera por las salinas y logrando un mayor depósito de sustancias y otras sales, obteniendo una sal de mejor calidad. Además, la extracción sostenible e integrada en el espacio protegido de este mineral puede mejorar la función de protección contra inundaciones que ejercen los humedales. 
El espacio protegido también proporciona un entorno físico que contribuye a nuestra salud nutricional, gracias a la asimilación de vitamina D. La vitamina D es producida por la piel de los seres humanos y de otros animales por acción los rayos UVB de la luz solar. A través de la acción C3 se frenarán los procesos erosivos del ecosistema dunar y de la playa, manteniendo un espacio óptimo para la afluencia del turismo, que encuentra en el Parque Regional un lugar donde poder beneficiarse de este servicio ecosistémico.

A continuación, se describen los servicios de Regulación y Mantenimiento (biótico) (Tabla 3):

Tabla 3. Servicios de regulación y mantenimiento para aquellos ecosistemas que dependen de organismos vivos

\begin{tabular}{|c|c|c|c|c|c|c|}
\hline Sección & División & Grupo & Clase & $\begin{array}{l}\text { Código } \\
\text { CICES } \\
\text { V5.1 }\end{array}$ & Servicio Ecosistémico & $\begin{array}{l}\text { Acción } \\
\text { LIFE }\end{array}$ \\
\hline \multirow{11}{*}{ 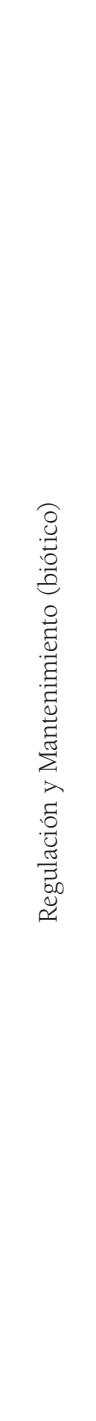 } & \multirow{11}{*}{$\begin{array}{c}\text { Regulación de } \\
\text { las condiciones } \\
\text { químicas, físicas } \\
\text { y biológicas }\end{array}$} & \multirow{3}{*}{$\begin{array}{l}\text { Regulación de flujos base } \\
\text { y fenómenos extremos }\end{array}$} & $\begin{array}{l}\text { Control de las tasas } \\
\text { de erosión }\end{array}$ & 2.2.1.1 & $\begin{array}{l}\text { Capacidad de la } \\
\text { vegetación para } \\
\text { estabilizar las dunas }\end{array}$ & $\mathrm{C} 3, \mathrm{D} 2$ \\
\hline & & & $\begin{array}{l}\text { Regulación y atenuación } \\
\text { del movimiento de masas }\end{array}$ & 2.2 .1 .2 & $\begin{array}{l}\text { Capacidad de la cubierta } \\
\text { forestal para prevenir y } \\
\text { mitigar el alcance y la } \\
\text { fuerza de las olas }\end{array}$ & $\mathrm{C} 3, \mathrm{D} 2$ \\
\hline & & & $\begin{array}{l}\text { Regulación del ciclo } \\
\text { hidrológico y del flujo } \\
\text { de agua (incluido el } \\
\text { control de inundaciones } \\
\text { y protección costera) }\end{array}$ & 2.2 .1 .3 & $\begin{array}{c}\text { Capacidad de la } \\
\text { vegetación (arribazones } \\
\text { de Posidonia oceanica) } \\
\text { para mitigar los efectos } \\
\text { de las influencias } \\
\text { costeras }\end{array}$ & $C 3, D 2$ \\
\hline & & \multirow{3}{*}{$\begin{array}{l}\text { Mantenimiento del } \\
\text { ciclo de vida, hábitat y } \\
\text { protección del acervo } \\
\text { genético }\end{array}$} & $\begin{array}{c}\text { Polinización } \\
\text { (o dispersión de 'gametos' } \\
\text { en un contexto marino) }\end{array}$ & 2.2.2.1 & Polinización & $\mathrm{C} 4$ \\
\hline & & & Dispersión de semillas & 2.2.2.2 & $\begin{array}{l}\text { Dispersión } \\
\text { de semillas }\end{array}$ & $\begin{array}{l}\mathrm{C} 1, \mathrm{C} 2, \\
\mathrm{C} 4\end{array}$ \\
\hline & & & $\begin{array}{l}\text { Mantenimiento } \\
\text { de las poblaciones } \\
\text { y los hábitats de cría } \\
\text { (incluida la protección } \\
\text { reserva genética) }\end{array}$ & 2.2 .2 .3 & $\begin{array}{l}\text { Mantenimiento de } \\
\text { hábitats donde viven el } \\
\text { conjunto de las especies }\end{array}$ & $\begin{array}{l}\mathrm{C} 1, \mathrm{C} 2, \\
\mathrm{C} 3, \mathrm{C} 4 \\
\mathrm{C} 5\end{array}$ \\
\hline & & $\begin{array}{l}\text { Control de plagas } \\
\text { y enfermedades }\end{array}$ & $\begin{array}{c}\text { El control de plagas } \\
\text { (incluyendo especies } \\
\text { invasoras) }\end{array}$ & 2.2.3.1 & $\begin{array}{l}\text { Control de Especies } \\
\text { Exóticas Invasoras }\end{array}$ & C5, D1 \\
\hline & & \multirow{2}{*}{$\begin{array}{l}\text { Regulación de la calidad } \\
\text { del suelo }\end{array}$} & $\begin{array}{c}\text { Procesos } \\
\text { de meteorización } \\
\text { y su efecto en la calidad } \\
\text { del suelo } \\
\end{array}$ & 2.2.4.1 & $\begin{array}{c}\text { Mantenimiento de } \\
\text { la calidad del suelo } \\
\text { gracias a la liberación de } \\
\text { nutrientes inorgánicos }\end{array}$ & \\
\hline & & & $\begin{array}{c}\text { Procesos } \\
\text { de descomposición } \\
\text { y de fijación y su efecto } \\
\text { en la calidad del suelo }\end{array}$ & 2.2 .4 .2 & $\begin{array}{l}\text { Mantenimiento de la } \\
\text { calidad del suelo gracias } \\
\text { a la descomposición de } \\
\text { materia orgánica }\end{array}$ & $\begin{array}{l}\mathrm{C} 1, \mathrm{C} 3, \\
\mathrm{C} 4\end{array}$ \\
\hline & & Condiciones del agua & $\begin{array}{l}\text { Regulación del estado } \\
\text { químico del agua salada } \\
\text { por procesos vivos }\end{array}$ & 2.2 .5 .2 & $\begin{array}{c}\text { Mantenimiento de las } \\
\text { condiciones químicas del } \\
\text { agua salada }\end{array}$ & $\mathrm{C} 1, \mathrm{C} 2$ \\
\hline & & $\begin{array}{l}\text { Composición } \\
\text { y condiciones } \\
\text { atmosféricas }\end{array}$ & $\begin{array}{c}\text { Regulación } \\
\text { de la composición } \\
\text { química de la atmósfera } \\
\text { y los océanos }\end{array}$ & 2.2.6.1 & $\begin{array}{l}\text { Sumidero de gases de } \\
\text { efecto invernadero } \\
\text { gracias a los seres vivos }\end{array}$ & $\begin{array}{l}\mathrm{C} 1, \mathrm{C} 2 \\
\mathrm{C} 3, \mathrm{C} 4\end{array}$ \\
\hline
\end{tabular}

Acciones del proyecto LIFE SALINAS relacionadas: Cl. Infraestructura verde: adecuación de motas con material autóctono del sustrato salinero, C2. Infraestructura verde: conexión de la charca de Coterillo con el circuito salinero, C3. Estabilización y refuerzo del ecosistema dunar de la playa de la Llana, C4. Revegetación con especies autóctonas en las dunas de la playa de Coterillo, C5. Potenciación de los servicios ambientales de los hábitats prioritarios a través del control de EEI, D1. Programa de seguimiento biológico, D2. Monitorización de las actuaciones de estabilización y refuerzo del ecosistema dunar de la playa de la Llana para el control de la erosión.

Elaboración propia

Las raíces de la vegetación que habita las dunas estabilizan y controlan la erosión, contribuyendo a un menor incremento de la pérdida de suelo. Gracias a la acción C3, se instalará una red de captadores de arena para frenar los procesos erosivos del cordón dunar, reteniendo la arena transportada por el viento y proporcionando un hábitat más duradero para la vegetación autóctona. La acción D2 evaluará 
las actuaciones de estabilización y refuerzo del cordón dunar de la acción C3 a través de su seguimiento. Algo similar es lo que ofrece el servicio ecosistémico "Capacidad de la cubierta forestal para prevenir y mitigar el alcance y la fuerza de las olas" que mediante el refuerzo con arena gracias a los captadores y su seguimiento, se reducirá la velocidad de movimiento del sistema dunar gracias a la estabilización por parte de la flora autóctona. Además, se plantea el uso de los arribazones de Posidonia oceanica como "muro" natural frente a la pérdida de arena. Estos restos naturales de plantas marinas no solo no se retiran de las playas del Parque Regional de las Salinas y Arenales de San Pedro del Pinatar, sino que gracias al Proyecto LIFE SALINAS se ha propuesto su apilamiento en el primer frente de duna, actuando como primer dique de protección e impidiendo que el agua del mar llegue a las charcas salineras durante los temporales.

Mediante la acción C4 de revegetación con especies autóctonas, se espera aumentar en 16.000 ejemplares de flora autóctona la cubierta vegetal, favoreciendo la polinización y la dispersión de semillas, servicios ecosistémicos que se verán beneficiados. Además, la adecuación de motas y el aumento de superficie de las mismas a través de las acciones $\mathrm{C} 1$ y C2, mejorará las condiciones de hábitat para la fauna en general y para las aves en particular, que con sus excrementos aportarán una fuente de nutrientes importante y ayudarán a la dispersión de semillas, manteniendo la fertilidad de los suelos.

Todas las acciones de conservación C1, C2, C3, C4 y C5 implican conservar y mejorar las condiciones ecológicas necesarias para el mantenimiento de las poblaciones donde viven el conjunto de las especies.

A través de la acción de control de las especies exóticas invasoras (C5) y su programa de seguimiento (D1) se controla y reduce el riesgo de invasión, evitando la competencia con especies autóctonas.

El mantenimiento de la calidad del suelo gracias a la descomposición de materia orgánica que mantendrá sus características necesarias para el uso humano, se verá beneficiado a través de las acciones $\mathrm{Cl}$, C3 y C4 de adecuación de motas, estabilización y refuerzo del ecosistema dunar y mediante la revegetación de especies autóctonas.

Las acciones $\mathrm{C} 1$ y C2 actúan sobre el circuito salinero, favoreciendo nuevas comunidades vegetales sumergidas, ayudando a la regulación y mantenimiento de las condiciones químicas del agua salina.

Las acciones C1, C2, C3 y C4 suponen un aporte en la regulación de las concentraciones de los gases de efecto invernadero gracias al secuestro por parte de la vegetación.

Como podemos ver en la siguiente tabla (Tabla 4), se describen los servicios de Regulación y Mantenimiento (abiótico):

Tabla 4. Servicios de regulación y mantenimiento para aquellos ecosistemas que no dependen de organismos vivos

\begin{tabular}{|c|c|c|c|c|c|c|}
\hline Sección & División & Grupo & Clase & $\begin{array}{l}\text { Código } \\
\text { CICES } \\
\text { V5.1 }\end{array}$ & Servicio Ecosistémico & $\begin{array}{l}\text { Acción } \\
\text { LIFE }\end{array}$ \\
\hline \multirow{3}{*}{ 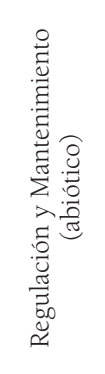 } & \multirow{2}{*}{$\begin{array}{l}\text { Transformación } \\
\text { de entradas } \\
\text { bioquímicas } \\
\text { o físicas a los } \\
\text { ecosistemas }\end{array}$} & \multirow{2}{*}{$\begin{array}{l}\text { La mediación de los } \\
\text { residuos, sustancias } \\
\text { tóxicas y otras molestias } \\
\text { por procesos no vivos }\end{array}$} & $\begin{array}{c}\text { La dilución de los } \\
\text { ecosistemas marinos y de } \\
\text { agua dulce }\end{array}$ & 5.1.1.1. & $\begin{array}{l}\text { El uso de sistemas } \\
\text { de agua marina } \\
\text { como sumidero de } \\
\text { contaminación }\end{array}$ & $\mathrm{Cl}, \mathrm{C} 2$ \\
\hline & & & Dilución por la atmósfera & 5.1.1.2 & $\begin{array}{l}\text { La atmósfera } \\
\text { como sumidero de } \\
\text { contaminación }\end{array}$ & $\mathrm{C} 4$ \\
\hline & $\begin{array}{c}\text { Regulación de } \\
\text { las condiciones } \\
\text { físicas, químicas y } \\
\text { biológicas }\end{array}$ & $\begin{array}{l}\text { Regulación de los flujos } \\
\text { de línea de base y los } \\
\text { fenómenos extremos }\end{array}$ & Flujos de masas & 5.2.1.1 & $\begin{array}{l}\text { Las dunas como } \\
\text { protección costera }\end{array}$ & $\mathrm{C} 3$ \\
\hline
\end{tabular}

Acciones del proyecto LIFE SALINAS relacionadas: Cl. Infraestructura verde: adecuación de motas con material autóctono del sustrato salinero, C2. Infraestructura verde: conexión de la charca de Coterillo con el circuito salinero, C3. Estabilización y refuerzo del ecosistema dunar de la playa de la Llana, C4. Revegetación con especies autóctonas en las dunas de la playa de Coterillo.

Elaboración propia

El agua supone un sumidero de contaminación, reduciendo la concentración de sustancias nocivas para el ser humano. Las acciones $\mathrm{Cl}$ y C2 favorecerán la circulación hídrica del circuito salinero, impidiendo el estancamiento de aguas y produciéndose una depuración natural de las mismas.

La atmósfera también actúa como sumidero de contaminación. A través de la revegetación con especies autóctonas en la acción C4, se aumentará en 2 hectáreas la superficie de vegetación, reduciendo la concentración de sustancias nocivas en la atmósfera. 
Las dunas actúan como barreras físicas frente al oleaje, que en casos extremos pero cada vez más frecuentes, provoca la llegada del agua del mar a las charcas salineras durante los temporales. Mediante la estabilización y refuerzo de las dunas en la acción C3, se reduce este impacto que produce pérdida de playas, pues las dunas son un reservorio de arena para ellas, y pérdidas económicas, ya que una entrada de agua del mar a las charcas desestabilizaría las concentraciones de sal en el circuito salinero, arruinándose el trabajo de todo un año.

En la última sección, se describen los Servicios Culturales (biótico) en la Tabla 5:

Tabla 5. Servicios culturales para aquellos ecosistemas que dependen de organismos vivos

\begin{tabular}{|c|c|c|c|c|c|c|}
\hline Sección & División & Grupo & Clase & $\begin{array}{l}\text { Código } \\
\text { CICES } \\
\text { V5.1 }\end{array}$ & Servicio Ecosistémico & $\begin{array}{l}\text { Acción } \\
\text { LIFE }\end{array}$ \\
\hline \multirow{10}{*}{ 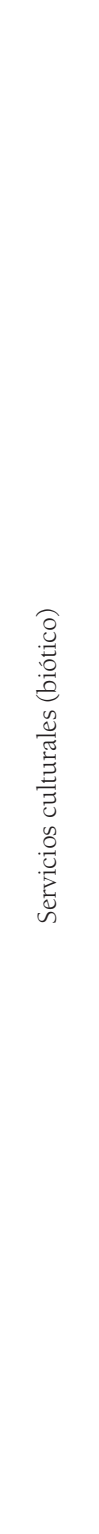 } & \multirow{6}{*}{$\begin{array}{l}\text { Interacciones } \\
\text { directas, in-situ } \\
\text { y al aire libre con } \\
\text { sistemas vivos } \\
\text { que dependen de } \\
\text { la presencia en el } \\
\text { entorno ambiental. }\end{array}$} & \multirow{2}{*}{$\begin{array}{l}\text { Interacciones físicas y } \\
\text { experimentales con el } \\
\text { entorno natural }\end{array}$} & $\begin{array}{l}\text { Características de los } \\
\text { sistemas vivos que per- } \\
\text { miten las actividades que } \\
\text { promueven la salud, la } \\
\text { recuperación o el disfrute } \\
\text { a través de interacciones } \\
\text { activas o de inmersión }\end{array}$ & 3.1.1.1 & Turismo deportivo & $\begin{array}{l}\mathrm{C} 1, \mathrm{C} 2 \\
\mathrm{C} 3, \mathrm{C} 4, \\
\mathrm{C} 5, \mathrm{D} 5\end{array}$ \\
\hline & & & $\begin{array}{l}\text { Características de los } \\
\text { sistemas vivos que per- } \\
\text { miten las actividades que } \\
\text { promueven la salud, la } \\
\text { recuperación o el disfrute } \\
\text { a través de interacciones } \\
\text { pasivas o de observación }\end{array}$ & 3.1.1.2 & Turismo de naturaleza & $\begin{array}{l}\mathrm{C} 1, \mathrm{C} 2 \\
\mathrm{C} 3, \mathrm{C} 4 \\
\mathrm{C} 5, \mathrm{D} 5\end{array}$ \\
\hline & & \multirow{4}{*}{$\begin{array}{l}\text { Interacciones intelectua- } \\
\text { les y representativas con } \\
\text { entorno natural }\end{array}$} & $\begin{array}{l}\text { Características de los } \\
\text { sistemas vivos que per- } \\
\text { miten la investigación } \\
\text { científica o la creación de } \\
\text { conocimientos ecológicos } \\
\text { tradicionales }\end{array}$ & 3.1.2.1 & Investigación científica & $\begin{array}{l}\text { D1, D2, } \\
\text { D5, E2 }\end{array}$ \\
\hline & & & $\begin{array}{l}\text { Características de los siste- } \\
\text { mas vivos que permiten la } \\
\text { educación y la formación }\end{array}$ & 3.1 .2 .2 & Educación ambiental & El \\
\hline & & & $\begin{array}{l}\text { Características de los } \\
\text { sistemas vivos que son } \\
\text { resonantes en términos de } \\
\text { cultura o el patrimonio }\end{array}$ & 3.1 .2 .3 & Patrimonio cultural & D5 \\
\hline & & & $\begin{array}{l}\text { Características de los sis- } \\
\text { temas vivos que permiten } \\
\text { las experiencias estéticas }\end{array}$ & 3.1.2.4 & Inspiración artística & D5 \\
\hline & \multirow{4}{*}{$\begin{array}{l}\text { Interacciones in- } \\
\text { directas o remotas } \\
\text { con sistemas vivos } \\
\text { que no requieren } \\
\text { presencia en el } \\
\text { entorno ambiental. }\end{array}$} & \multirow{2}{*}{$\begin{array}{l}\text { Interacciones espirituales, } \\
\text { simbólicas y de otro tipo } \\
\text { con el entorno natural. }\end{array}$} & $\begin{array}{l}\text { Elementos de los sistemas } \\
\text { vivos que tienen un signi- } \\
\text { ficado simbólico }\end{array}$ & 3.2 .1 .1 & Icono cultural & D5 \\
\hline & & & $\begin{array}{c}\text { Elementos de los sistemas } \\
\text { vivos utilizados para el } \\
\text { entretenimiento o repre- } \\
\text { sentación }\end{array}$ & 3.2 .1 .3 & $\begin{array}{l}\text { Documentales/reporta- } \\
\text { jes en la naturaleza }\end{array}$ & El \\
\hline & & \multirow{2}{*}{$\begin{array}{l}\text { Otras características bió- } \\
\text { ticas que tienen un valor } \\
\text { de no uso }\end{array}$} & $\begin{array}{c}\text { Características o rasgos } \\
\text { de los sistemas vivos que } \\
\text { tienen un valor de exis- } \\
\text { tencia }\end{array}$ & 3.2 .2 .1 & $\begin{array}{l}\text { Valor de existencia. } \\
\text { Bienestar moral/mental }\end{array}$ & $\begin{array}{l}\mathrm{C} 1, \mathrm{C} 2 \\
\mathrm{C} 3, \mathrm{C} 4 \\
\quad \mathrm{C} 5\end{array}$ \\
\hline & & & $\begin{array}{c}\text { Características o rasgos } \\
\text { de los sistemas vivos que } \\
\text { tienen una opción o valor } \\
\text { de legado }\end{array}$ & 3.2 .2 .2 & $\begin{array}{l}\text { Valor de legado (me- } \\
\text { diante la protección de } \\
\text { especies en peligro) }\end{array}$ & D5 \\
\hline
\end{tabular}

Acciones del proyecto LIFE SALINAS relacionadas: C1. Infraestructura verde: adecuación de motas con material autóctono del sustrato salinero, C2. Infraestructura verde: conexión de la charca de Coterillo con el circuito salinero, C3. Estabilización y refuerzo del ecosistema dunar de la playa de la Llana, C4. Revegetación con especies autóctonas en las dunas de la playa de Coterillo, C5. Potenciación de los servicios ambientales de los hábitats prioritarios a través del control de EEI, Dl. Programa de seguimiento biológico, D2. Monitorización de las actuaciones de estabilización y refuerzo del ecosistema dunar de la playa de la Llana para el control de la erosión, D5. Evaluación del impacto socio-económico y de los servicios de los ecosistemas, El. Planificación y ejecución de la difusión, E2. Replicabilidad, transferibilidad y cooperación. 
Gracias a todas las acciones concretas de conservación del Proyecto LIFE SALINAS C1, C2, C3, C4 y C5 que implican conservar y mejorar las condiciones ecológicas del espacio protegido, todas las actividades turísticas deportivas, de naturaleza, de salud, etc. se verán beneficiadas. Así mismo, el grado de satisfacción con respecto al turismo será evaluado gracias a la acción D5, mediante encuestas de satisfacción, tal y como se detalla en el presente estudio.

La investigación científica se promueve desde la Universidad de Murcia a través de las acciones D1, D2, D5 y E2 a través del seguimiento biológico, la evaluación y la replicabilidad de las actuaciones.

También es posible y necesaria la difusión de la ejecución del Proyecto y sus resultados a través de una completa campaña de educación ambiental y voluntariado dirigida a todas las personas que puedan verse afectadas o estén interesadas gracias a la acción El. La creación de documentales y/o reportajes en la naturaleza también están incluidos en esta acción.

Los atributos de la naturaleza proporcionan a ser humano un valor de existencia y un bienestar mo$\mathrm{ral} / \mathrm{mental}$. Consideramos que todas las acciones de conservación del Proyecto contribuyen a la mejora y estabilidad del espacio natural protegido, a su continuidad en el tiempo.

La conservación del patrimonio cultural, el fomento de la inspiración artística, la consideración de las salinas de San Pedro del Pinatar como un icono cultural y los atributos de la naturaleza que queremos que generaciones futuras puedan disfrutar (valor de legado), son acciones que se evaluarán a través de las encuestas que se realizarán en el marco de la acción D5. Lo mismo ocurre con los servicios ecosistémicos de la siguiente tabla (Tabla 6), donde el turismo en el que prima la sostenibilidad y la conservación, las actividades recreativas con responsabilidad y compromiso de conservación, las características naturales que tienen una importancia simbólica o espiritual y/o un significado cultura o de legado serán evaluadas en la acción D5.

Por último, se describen en la Tabla 6 los Servicios Culturales (abiótico) de este apartado de servicios ecosistémicos:

Tabla 6. Servicios culturales para aquellos ecosistemas que no dependen de organismos vivos

\begin{tabular}{|c|c|c|c|c|c|c|}
\hline Sección & División & Grupo & Clase & $\begin{array}{l}\text { Código } \\
\text { CICES } \\
\text { V5.1 }\end{array}$ & Servicio Ecosistémico & $\begin{array}{l}\text { Acción } \\
\text { LIFE }\end{array}$ \\
\hline \multirow{4}{*}{ 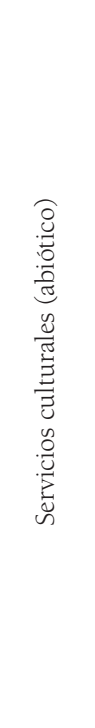 } & \multirow{2}{*}{$\begin{array}{l}\text { Interacciones } \\
\text { directas, in situ y } \\
\text { al aire libre con } \\
\text { sistemas físicos } \\
\text { naturales que } \\
\text { dependen de la } \\
\text { presencia en el } \\
\text { entorno ambiental. }\end{array}$} & $\begin{array}{c}\text { Interacciones físicas } \\
\text { y experimentales con } \\
\text { componentes abióticos } \\
\text { naturales del medio } \\
\text { ambiente. }\end{array}$ & $\begin{array}{c}\text { Características naturales } \\
\text { y abióticas de la } \\
\text { naturaleza que permiten } \\
\text { interacciones físicas o } \\
\text { experimentales activas o } \\
\text { pasivas. }\end{array}$ & 6.1 .1 .1 & Ecoturismo & D5 \\
\hline & & $\begin{array}{c}\text { Interacciones } \\
\text { intelectuales y } \\
\text { representativas con } \\
\text { componentes abióticos } \\
\text { del medio ambiente } \\
\text { natural }\end{array}$ & $\begin{array}{c}\text { Características } \\
\text { naturales y abióticas } \\
\text { de la naturaleza que } \\
\text { permiten interacciones } \\
\text { intelectuales }\end{array}$ & 6.1 .2 .1 & Recreación & D5 \\
\hline & \multirow{2}{*}{$\begin{array}{c}\text { Interacciones } \\
\text { indirectas o remotas } \\
\text { con sistemas físicos } \\
\text { que no requieren } \\
\text { presencia en el } \\
\text { entorno ambiental. }\end{array}$} & $\begin{array}{c}\text { Interacciones espirituales, } \\
\text { simbólicas u otras } \\
\text { con los componentes } \\
\text { abióticos del medio } \\
\text { natural }\end{array}$ & $\begin{array}{c}\text { Características naturales } \\
\text { y abióticas de la } \\
\text { naturaleza que permiten } \\
\text { interacciones espirituales, } \\
\text { simbólicas u otras }\end{array}$ & 6.2 .1 .1 & Importancia simbólica & D5 \\
\hline & & $\begin{array}{l}\text { Otras características } \\
\text { abióticas que tienen un } \\
\text { valor de no uso }\end{array}$ & $\begin{array}{l}\text { Características naturales, } \\
\text { abióticas o de la } \\
\text { naturaleza que tienen } \\
\text { un valor de existencia, } \\
\text { opción o legado. }\end{array}$ & 6.2 .2 .1 & $\begin{array}{l}\text { Significado cultural/ } \\
\text { Legado }\end{array}$ & D5 \\
\hline
\end{tabular}

Acciones del proyecto LIFE SALINAS relacionadas: D5. Evaluación del impacto socio-económico y de los servicios de los ecosistemas.

Elaboración propia

Una vez identificados todos los servicios ecosistémicos, se incluye en la encuesta final cinco desplegables con todos ellos, de forma que los participantes elijan y ordenen del 1 al 5 aquellos que le reportan más utilidad, siendo 1 el más relevante y 5 el menos relevante. De esta forma, se crea un ranking en el que el encuestado tiene acceso a todos los servicios ecosistémicos que actualmente ofrece el Parque Regional, 
ordenándolos según sus preferencias, por lo que obtenemos la respuesta por Experimentos de Elección en la modalidad de ranking contingente. A continuación, realizarán una Valoración Contingente a través de la disposición a pagar, eligiendo una de las 4 opciones de respuesta cerrada antes mencionadas.

\subsection{Partes interesadas (stakeholders)}

Para la realización de la encuesta final han sido consideradas varias tipologías de agentes relevantes o usuarios de los servicios ecosistémicos. Por tanto, la clasificación de las partes interesadas objeto de las encuestas es:

- Turistas y residentes

- Administración: Personas vinculadas con la Administración General (Gobierno Autonómico) o Local (Ayuntamientos) responsable de la conservación y gestión del Parque Regional

- Personas vinculadas con Asociaciones ecologistas, deportivas, federaciones, etc.

- Empresarios, emprendedores, trabajadores y otras personas vinculadas con el sector turístico.

- Agentes culturales y científicos (Universidades, asociaciones culturales, etc.)

\section{Discusión de resultados}

El Parque Regional de las Salinas y Arenales de San Pedro del Pinatar posee multitud de servicios ecosistémicos que hasta ahora no han sido identificados ni analizados. Dado que el espacio protegido acoge de media 310.000 visitantes al año, se pretende realizar un estudio socioeconómico obtenido los resultados de 2.600 encuestas, permitiendo un margen de error del 3\% y un nivel de confianza del 97\%. Se consideró en primer lugar necesaria la realización de un 10\% de encuestas pre-test, que proporcionaron información muy valiosa de cara a la redacción de las encuestas finales: se obtuvo el valor central de la subasta que aparecerá en las preguntas de valoración económica y ayudó a orientar el lenguaje y la forma de dirigirse al entrevistado.

Otros estudios como el de Martínez-Paz et al. (2008) ya obtuvieron información importante a través de encuestas, utilizando los métodos de Valoración Contingente y de Experimentos de Elección en su variante de Ranking Contingente para el Parque Regional de Calblanque, Monte de las Cenizas y Peña del Águila (Murcia, España). Con sus estudios se llegó a la conclusión de que es importante incorporar la valoración social de los visitantes al espacio protegido.

Paralelo a este análisis, se realizó una profunda revisión de todos los servicios ecosistémicos que puede albergar este enclave natural. Hasta ahora se han identificado 32 servicios, que serán objeto de valoración económica por parte de los participantes en la encuesta final, teniendo como opciones de respuesta: Nada, aportación de 2,5 €/año, aportación de $5 € /$ año y aportación de 7,5 €/año, de acuerdo con la información extraída en el análisis de las encuestas pre-test.

El estudio de los servicios ecosistémicos proporcionará información científica sobre su actual situación y su posible evolución, ampliando la información que se tiene de los ecosistemas y su biodiversidad y ayudando en una mejor gestión del espacio protegido por parte de políticos y gestores.

\section{Conclusiones}

El turismo es una importante fuente de ingresos en la economía española. Un turismo mal gestionado puede suponer una amenaza para enclaves tan sensibles como el Parque Regional de las Salinas y Arenales de San Pedro del Pinatar. La gestión adecuada del turismo puede permitir aunar desarrollo económico y conservación.

El análisis de los servicios ecosistémicos que ofrece el Parque Regional de las Salinas y Arenales de San Pedro del Pinatar y su evaluación a través de encuestas por parte de los usuarios del mismo, puede incrementar en los visitantes un valor de legado, respeto y pertenencia al medio natural.

La información obtenida en las encuestas pre-test ha servido para mejorar el diseño de las encuestas finales. Los atributos seleccionados para las valoraciones económicas del Parque Regional pasaron de ser 7 en la encuesta pre-test (los objetivos principales del Proyecto LIFE SALINAS) a 32 en el diseño de las encuestas finales (los 32 servicios ecosistémicos considerados por el grupo de trabajo del Proyecto y que integran los anteriores atributos). 
En el análisis de las encuestas pre-test de nuestro estudio, la opción de aportar menos de $5 €$ /año fue la más elegida en cada pregunta, alrededor de la cual se eligieron tres opciones más para los ejercicios de valoración económica.

Las encuestas finales recogerán además el aspecto económico como el gasto realizado y su disposición a pagar por el acceso al bien a través de la Valoración Contingente y de Experimentos de Elección. Por lo tanto, las encuestas no solo arrojarán datos sobre preferencias, gasto económico, etc., sino que además proporcionarán un cauce de comunicación entre el encuestador y el encuestado, mejorando así el conocimiento que este tenga sobre el Parque Regional y dándole la oportunidad de expresar las opiniones que puedan contribuir a una mejor gestión del espacio protegido.

Los resultados de las evaluaciones pueden contribuir en la toma de decisiones respecto a políticas y normativas de gestión, derivando en una correcta protección y ordenación del espacio protegido.

\section{Financiación}

Este artículo se ha realizado gracias a la financiación de la Unión Europea, a través del Proyecto LIFE17 NAT/ES/000184 Conservación de los hábitats y aves acuáticas en el LIC y ZEPA ES0000175 "Salinas y Arenales de San Pedro del Pinatar" (LIFE SALINAS).

\section{Referencias}

Alcón, F. J. y López, E. I. (2017). Plan de gestión integral de los espacios protegidos del Mar Menor y la Franja Litoral Mediterránea de la Región de Murcia. Informe de Evaluación Socioeconómica. Cartagena: Universidad Politécnica de Cartagena.

Azqueta (1994). Valoración económica de la calidad ambiental. Madrid: McGraw-Hill.

Ballesteros, G. A. (2014a). Configuración del paisaje en las explotaciones salineras litorales mediterráneas: El caso de las salinas de San Pedro del Pinatar (Murcia, España). Anales de Geografía, 34(1), 33-59. https://doi.org/10.5209/rev_AGUC.2014.v34.n1.45191

Ballesteros, G. A. (2014b). Afluencia de visitantes en el Parque Regional de las Salinas y Arenales de San Pedro del Pinatar (Murcia). Papers de turisme, 55, 24-42. Recuperado de http://www.papersdeturisme. gva.es/ojs/index.php/Papers/article/view/183

Ballesteros, G. A. y Fernández, J. F. (2013). La explotación industrial de las Salinas de San Pedro del Pinatar (Murcia). Papeles de Geografia, (57-58), 55-68. Recuperado de https://revistas.um.es/geografia/article/ view/191251

Bengochea A., Fuertes A.M. y del Saz S. (2003). Estudio de las preferencias individuales sobre un espacio natural mediante el análisis conjunto. Working Papers. Serie EC 2003-08, Instituto Valenciano de Investigaciones Económicas, S.A. (Ivie). Recuperado de https://www.ivie.es/es_ES/investigacion/ publicaciones/documento/2003-8-estudio-de-las-preferencias-individuales-sobre-un-espacionatural-mediante-el-analisis-conjunto/

Bishop, R. C. y Heberlein, T. A. (1979). Measuring Values of Extramarket Goods: Are Indirect Measure Biased? American Journal of Agricultural Economics, 61, 926-30. https://doi.org/10.2307/3180348

De Groot R.S., Alkemade R., Braat L., Hein L. y Willemen L. (2009). Challenges in integrating the concept of ecosystem services and values in landscape planning, management and decision making. Ecological Complexity, 7, 260-272 https://doi.org/10.1016/j.ecocom.2009.10.006

Dirección General de Medio Ambiente (2014). Consejería de Agricultura y Agua de la Región de Murcia. Memoria anual de gestión 2014. Recuperado de http://www.murcianatural.carm.es/c/document_library/ get_file?uuid=01715493-123d-48fd-896b-al73e9f876e5\&groupId=14

Espinal, N.E. y Gómez, J.D. (2011). Experimentos de elección: una metodología para hacer valoración económica de bienes de no mercado. Ensayos de Economía, 21, 38. Recuperado de https://revistas.unal. edu.co/index.php/ede/article/view/27941

Fernández, A., López J.M. y Such M.J. (2017). El sector turístico en España: el reto de mantener el liderazgo en competitividad. Política Económica, Economía Regional y Servicios. Capítulo XXVII, 557-578. 
Grajales, P. A. (2005). Valoración contingente del impacto ambiental de la construcción de la infraestructura vial del proyecto hidroeléctrico Porce III: aplicación a las microcuencas del área de influencia directa. Ensayos de Economía, 15, 26, 124-160. Recuperado de https://revistas.unal.edu.co/index.php/ede/ article/view/24665

Haines-Young, R. y Potschin M.B. (2018). Common International Classification of Ecosystem Services (CICES) V5.1 and Guidance on the Application of the Revised Structure. Recuperado de https://cices.eu/ content/uploads/sites/8/2018/01/Guidance-V51-01012018.pdf

Hernández, S. (2010). Valoración económica ambiental del ecosistema ripario en la cuenca alta del río San Pedro-Mezquital (Tesis de Maestría). Instituto Politécnico Nacional. Durango.

Leal-Rojas, C. L. (2005). Valoración Económica del Medio Ambiente: Caso de la Reserva de la Biosfera de los Tuxtlas (Tesis Licenciatura). Economía. Departamento de Economía, Escuela de Ciencias Sociales, Universidad de las Américas Puebla. México. Recuperado de http://catarina.udlap.mx/u_dl_a/tales/ documentos/lec/leal_r_cl/

León, C.J. y F.J. Vásquez-Polo (2000). Modelización del aprendizaje en valoración contingente. Investigaciones Económicas, 24(1), 117-138. Recuperado de http://www.tebadm.ulpgc.es/almacen/ fjvpolo/v24ila4.pdf

Maes J., Teller A., Erhard M., Grizzetti B., Barredo J.I., ... y Werner B. (2018). Mapping and Assessment of Ecosystems and their Services: An analytical framework for ecosystem condition. Publications office of the European Union, Luxembourg. http://dx.doi.org/10.2779/055584

Maldonado, J.H. y Cuervo, R. (2016). Valoración económica del Parque Nacional Natural Corales de Profundidad. Boletín de Investigaciones Marinas y Costeras, 45(1), 99-121. http://dx.doi.org/10.25268/ bimc.invemar.2016.45.1.632

Martínez-Aedo, M.A., Páez, M. y López, M. (2008). Valoración económico-ambiental del parque regional de Sierra Espuña. Murcia: Ed. Consejería de Agricultura y Agua. Dirección General de Patrimonio Natural y Biodiversidad. Recuperado de http://www.murcianatural.carm.es/web/guest/visor-contenidos-di namicos;jsessionid=7459316D94122F76939F504183AA2996?p_p_id=20\&p_p_lifecycle=1\&p_p_

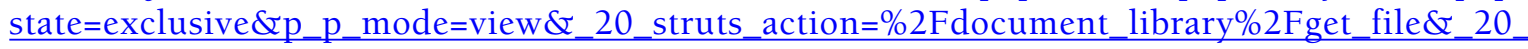
folderId=103839\&_20_name=DLFE-1335.pdf

Martínez-Carrasco, F., Martínez-Paz, J.M. y Esteve, M.A. (2012). Políticas de gestión y valoración económica del Parque Regional de Calblanque, Monte de las Cenizas y Peña del Águila. En M.A. Esteve, J.M. Martínez-Paz, B. Soro (Ed.), Los Espacios Naturales Protegidos de la Región de Murcia: Estudio de casos desde una perspectiva interdisciplinar (pp. 261-282). Murcia: Editum.

Martínez-Paz, J., Esteve-Selma, M. y Belmonte, J. (2007). Sesgo estratégico en la Valoración Contingente de un espacio natural: el parque regional Cabo-Cope Puntas de Calnegre (Murcia). Comunicación presentada al IV congreso Nacional de Economía Agraria. Albacete.

Martínez-Paz, J.M., Martínez-Carrasco, F., Estéve, M.A., Fructuoso y E., Navalón, E. (2008). Valoración económica y políticas de gestión en el Parque Regional de Calblanque, Monte de las Cenizas y Peña del Águila (Murcia). Comunicación presentada al III Congreso de la Asociación Hispano-Portuguesa de Economía de los Recursos Naturales y Ambientales. Palma de Mallorca.

Martínez-Paz, J.M., Perni A. y Almansa, C. (2012). El Parque Regional de Sierra Espuña: valor económico y políticas de gestión. En M.A. Esteve, J.M. Martínez-Paz, B. Soro (Ed.), Los Espacios Naturales Protegidos de la Región de Murcia: Estudio de casos desde una perspectiva interdisciplinar (pp. 283-310). Murcia: Editum.

Martínez-Paz, J.M., Fernández-Ferrer, J.R., Pellicer-Martínez, F., Robledano-Aymerich, F., EsteveSelma, M.A., Fariñós-Celdrán, P. y Carreño-Fructuoso, F. (2015). Evaluación Multicriterio del Acondicionamiento de Humedales: Las encañizadas del Mar Menor, Murcia. X Congreso de Economia Agraria (pp. 85-94). Córdoba: Asociación Española de Economía Agraria.

Martínez Quintana, V. (2017). El turismo de naturaleza: un producto turístico sostenible. Arbor, 193(785), a396. http://dx.doi.org/10.3989/arbor.2017.785n3002

Millennium Assessment (2003). Ecosystems and Human Well-being. A Framework for assessment. Washington: Island Press. Recuperado de http://pdf.wri.org/ecosystems_human_wellbeing.pdf 
Millennium Assessment (2005). Ecosystems and Human Well-being. Synthesis. Washington, DC: Island Press. Recuperado de https://www.millenniumassessment.org/documents/document.356.aspx.pdf

Montes, C. y Sala, O. (2007). La Evaluación de los Ecosistemas del Milenio. Las relaciones entre el funcionamiento de los ecosistemas y el bienestar humano. Ecosistemas, 16(3), 137-147. Recuperado de https://www.revistaecosistemas.net/index.php/ecosistemas/article/view/120

Oficina de Impulso Socioeconómico del Medio Ambiente (2018). Memoria anual de gestión 2018. Consejería de Empleo, Universidades, Empresa y Medio Ambiente de la Región de Murcia. Recuperado de http://www.murcianatural.carm.es/c/document_library/get_file?uuid=914fb749-7f31-43d5-a0b3Od248701f4b4\&groupId $=14$

Perni, A., Martínez-Carrasco, F. y Martínez-Paz, J.M. (2011). Valoración económica de la restauración ambiental de lagunas costeras: el Mar Menor (SE España). Ciencias Marinas, 37(2), 175-190. https:// doi.org/10.7773/cm.v37i2.1889

Riera, P. (1994). Manual de Valoración Contingente. Madrid, Ministerio de Economía y Hacienda. Instituto de Estudios Fiscales. Recuperado de https://pagines.uab.cat/pere.riera/content/manual-devaloraci\%C3\%B3n-contingente

Romero, C. (1997). Economía de los recursos ambientales y naturales. Alianza Editorial.

Sánchez U., J.M. (2013). Valoración contingente y experimentos de elección aplicados en el Parque Nacional Sierra Nevada, Venezuela. Economía, XXXVIII(35), 57-100. Recuperado de https://www. redalyc.org/articulo.oa?id=195632394003

Segado, I. y Castro, J.P. (2003). Valor económico de una mejora y conservación de la calidad ambiental del Mar Menor. En M.A. Esteve, M. Lloréis y C. Martínez (Eds.), Los recursos naturales de la Región de Murcia. Un análisis interdisciplinar (pp. 208-212). Universidad de Murcia.

Valls, F. (1923). Los privilegios de Alfonso X y la Ciudad de Murcia. Inauguración del curso 1923-1924. Universidad de Murcia.

Vázquez, M.X. y Prada A. (2003). Valoración Económica de Alternativas de Gestión en Paisajes de Montaña de la Red Natura 2000. Ponencia presentada en el VI Encuentro de Economía Aplicada. Universidad de Vigo.

Vizcaíno, M.L. (2015). Evolución del turismo en España: el turismo cultural. International Journal of Scientific Management and Tourism, 4, 75-95. Recuperado de http://www.ijosmt.com/index.php/ijosmt/ article/view/53

Welsch, H. y J. K. Uhling (2009). Using happiness data for environmental valuation: issues and applications. Journal of EconomicSurveys, 23(2), 385-406. https://doi.org/10.1111/j.1467-6419.2008.00566.x 